\title{
Development of a real time polymerase chain reaction assay for equine encephalosis virus
}

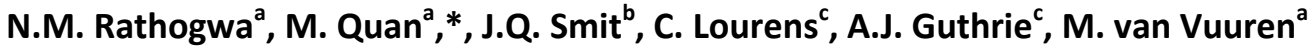 \\ ${ }^{a}$ Department of Veterinary Tropical Diseases, Faculty of Veterinary Science, University of Pretoria, Private Bag \\ X04, Onderstepoort, 0110, South Africa. \\ ${ }^{b}$ Division of Molecular Biosciences, Imperial College London, Exhibition Road, London SW72AZ, United \\ Kingdom. \\ c Equine Research Centre, Faculty of Veterinary Science, University of Pretoria, Private Bag X04, \\ Onderstepoort, 0110, South Africa. \\ *Corresponding author at: Department of Veterinary Tropical Diseases, Faculty of Veterinary Science, \\ University of Pretoria, Private Bag X04, Onderstepoort, 0110, South Africa. \\ Tel.: +27 12 5298142; fax: +27 125298312 . \\ E-mail address: melvyn.quan@up.ac.za (M. Quan).
}

E-mail:

N.M. Rathogwa: rmaclaughlin@yahoo.com J. Smit: joshua.smit09@imperial.ac.uk

C. Lourens: carina.lourens@up.ac.za

A.J. Guthrie: alan.guthrie@up.ac.za

M. van Vuuren: moritz.vanvuuren@up.ac.za

\section{Abstract}

Equine encephalosis virus (EEV) is the cause of equine encephalosis. The disease is similar to mild forms of African horse sickness (AHS) and the two diseases are easily confused. Laboratory identification and serotyping of EEV is based on viral isolation in BHK-21 cells and a viral plaque inhibition neutralization test. These procedures are time-consuming and therefore a more rapid diagnostic assay for EEV that can distinguish EEV from African horse sickness virus (AHSV) infections was developed.

The S7 (VP7) gene from $38 \mathrm{EEV}$ isolates representing all seven serotypes was amplified and sequenced. A conserved region at the $5^{\prime}$ end of the gene was identified and used to design groupspecific EEV primers and a TaqMan ${ }^{\circledR}$ MGB $^{\text {TM }}$ hydrolysis probe.

The efficiency of the EEV real-time RT-PCR assay was $81 \%$. The assay was specific, as it did not detect any of the nine serotypes of AHSV, nor 24 serotypes of bluetongue virus (BTV) and sensitive, with a $95 \%$ limit of detection of $10^{2.9} \mathrm{TCID}_{50} / \mathrm{ml}$ blood (95\% confidence interval: $10^{2.7}-10^{3.3}$ ).

The real-time format was selected because of its convenience, sensitivity and ability to produce results rapidly. 
Keywords: equine encephalosis virus; real time RT-PCR; orbivirus; diagnostic assay; group- specific; VP7

\section{Highlights}

- The $\mathbf{S 7}$ genes of $38 \mathrm{EEV}$ isolates were sequenced.

- A real-time RT-PCR assay for equine encephalosis virus was developed.

- The $95 \%$ limit of detection of the EEV assay was $10^{2.9} \mathrm{TCID}_{50}$.

- The assay was specific for EEV and did not detect other orbiviruses (BTV, AHSV).

\section{Introduction}

Equine encephalosis was first described by Sir Arnold Theiler, who described a fever in horses that simulated African horse sickness (AHS), which he called "ephemeral fever" (Theiler, 1910). Theiler differentiated the disease from AHS on clinical signs (incubation period and temperature characteristics) and transmission experiments. Equine encephalosis virus (EEV) was isolated in 1967 from a Thoroughbred mare named Cascara from the Kimberley district of South Africa. Clinical signs of the affected horse included listlessness, tightening of the muscles of the face, a high temperature and an elevated pulse rate about $24 \mathrm{~h}$ before death. The virus was also recovered from blood samples taken from other horses on the same farm which had exhibited no clinical signs except a febrile reaction (Erasmus et al., 1970).

Equine encephalosis is endemic to southern Africa (Barnard, 1997; Venter et al., 1999) and the seroprevalence is more than $75 \%$ in horses and in donkeys $85 \%$ (Venter et al.. 1999). In Thoroughbred horses the seroprevalence of neutralizing antibodies against one or more serotypes of the EEV was 56.9 \% (Howell et al., 2002). Antibodies against EEV have been demonstrated in zebra and African elephant (Barnard, 1997; Williams et al., 1993).

EEV infection in horses was been reported recently in Israel and involved approximately 150 cases with no reported mortalities (Aharonson-Raz et al., 2011; Mildenberg et al., 2009). Circulation of EEV in Ethiopia, Ghana and The Gambia has also been reported recently (Oura et al., 2012).

EEV is transmitted between equid hosts by the bites of Culicoides spp. midges (Diptera: Ceratopogonidae), specifically C. imicola, which is regarded as the main vector of EEV (Paweska et al., 1999; Venter et al., 1999). C. imicola is the most abundant vector of the Culicoides species associated with livestock in the summer rainfall region of southern Africa. The first isolation of an EEV strain from Culicoides species in South Africa was done by Theodoridis et al. (1979). Since then, C. bolitinos has also been confirmed as a vector for EEV (Paweska and Venter, 2004).

EEV is a member of genus Orbivirus in the family Reoviridae, subfamily Sedoreovirinae consisting of species such as AHSV, bluetongue virus (BTV), and epizootic hemorrhagic disease virus (EHDV) with similar structural morphology and functional properties. The genome of EEV is similar to those of other orbiviruses and consists of ten double-stranded (ds) RNA segments encapsulated by a doublelayered icosahedral shell. Each of the segments codes for a viral protein, namely seven structural proteins (VP1 to VP7) and non- structural proteins (NS1, NS2, NS3/NS3a, NS4) (Belhouchet et al., 2011; Firth, 2008; Mertens et al., 1984; Ratinier et al., 2011). 
There are seven serotypes of EEV. These are EEV-1 (Bryanston), EEV-2 (Cascara), EEV-3 (Gamil), EEV4 (Kaalplaas), EEV-5 (Kyalami), EEV-6 (Potchefstroom), and EEV-7 (E21/20) (Gorman et al., 1983; Howell et al., 2002).

Most EEV infections are subclinical in nature and mild forms are confused easily with mild forms of African horse sickness virus (AHSV) infections, as both infections exhibit similar clinical signs (Howell et al., 2004). This makes diagnosis difficult and laboratory tests are needed to differentiate the diseases. There are various laboratory methods used in the diagnosis of EEV infection. Isolation of the virus is performed in baby hamster kidney (BHK) cells, suckling mice brains, or embryonated hen's eggs (Erasmus et al., 1970). The virus is serotyped by the plaque inhibition neutralization assay (Quan et al., 2008). A serological group-specific, indirect sandwich enzyme-linked immunosorbent assay (ELISA) is available for the detection of EEV antigen (Crafford et al., 2003). Tests for antibody detection include complement fixation (CF), agar gel immunodiffusion (AGID) or indirect immunofluorescent antibody (IFA) tests (Howell et al., 2004). The disadvantages of these methods are that they are time-consuming and only provide a retrospective diagnosis.

To date, no reverse transcription polymerase chain reaction (RT-PCR)-based assay for the detection of EEV nucleic acid has been described. Real-time RT-PCR provides several advantages over the use of conventional PCR and ELISA, including rapid turn-around with high analytical specificity, sensitivity and a reduced risk for contamination. As the clinical signs of AHSV and EEV infections in equines may be difficult to distinguish a rapid and reliable diagnostic real-time RT-PCR assay for EEV is needed to for rapid diagnosis of this infection.

This paper describes the development and optimisation of a real-time RT-PCR assay for the sensitive and specific detection of EEV in samples from horses infected naturally with EEV. This was accomplished by sequencing the S7 (VP7) gene of $38 \mathrm{EEV}$ isolates representing all seven serotypes and identifying a conserved region for the design of an EEV real-time RT-PCR assay using a TaqMan ${ }^{\circledR}$ $\mathrm{MGB}^{\mathrm{TM}}$ hydrolysis probe. Critical control parameters of the assay, as well as the repeatability, analytical sensitivity and specificity of the assay were estimated.

\section{Materials and methods}

\subsection{Development of EEV real-time RT-PCR assay}

An EEV S7 (VP7) gene sequence (FJ183391) obtained from GenBank ${ }^{\circledast}$

(www.ncbi.nlm.nih.gov/genbank) was used with FastPCR software V6.1.47 (Kalendar et al., 2009) to design terminal primers for amplification and sequencing of the EEV S7 gene.

EEV isolates representing all seven recognized serotypes of EEV were sequences (Table 1).

Viral dsRNA was extracted from EEV cell culture isolates. The contents of a flask were agitated and $500 \mu \mathrm{l}$ transferred to a $1.5 \mathrm{ml}$ eppendorf tube. Samples were spun at $11000 \mathrm{~g}$ for $5 \mathrm{~min}$ in a 5417C centrifuge (Eppendorf). The supernatant was discarded and the cell pellet mixed with $50 \mu \mathrm{l}$ of phosphate buffered saline (PBS). Total nucleic acid extractions from the cell pellet were performed using a MagMax ${ }^{\mathrm{TM}}-96$ Total RNA Isolation kit (Lifetech), according to the manufacturer's instructions. The samples were processed in a MagMax ${ }^{\mathrm{TM}}$ Express Particle Processor (Lifetech) and a custom 
Table 1 : EEV isolates used for sequencing of the S7 (VP7) gene.

\begin{tabular}{|c|c|c|c|c|}
\hline Name & Serotype & Passage number & Isolation date & GenBank \\
\hline Reference strain & 1 (Bryanston) & 1 & $2004 / 11 / 26$ & KF483827 \\
\hline E080099 & 1 (Bryanston) & 6 & 2008/07/03 & KF483807 \\
\hline E080243 & 1 (Bryanston) & 6 & $2008 / 08 / 14$ & KF483814 \\
\hline E080340_1 & 1 (Bryanston) & 3 & 2009/02/19 & KF483816 \\
\hline E080341_2 & 1 (Bryanston) & 3 & $2009 / 02 / 19$ & KF483817 \\
\hline E080342 & 1 (Bryanston) & 3 & $2009 / 02 / 12$ & KF483818 \\
\hline E090039 & 1 (Bryanston) & 4 & 2009/04/03 & KF483823 \\
\hline E090047 & 1 (Bryanston) & 3 & 2009/04/03 & KF483798 \\
\hline E090059 & 1 (Bryanston) & 1 & 2009/04/09 & KF483824 \\
\hline Reference strain & 2 (Cascara) & 3 & 2002/09/09 & KF483795 \\
\hline E100043 & 2 (Cascara) & - & 2010/05/06 & KF483796 \\
\hline Reference strain & 3 (Gamil) & - & 1998/08/06 & KF483828 \\
\hline Reference strain & 4 (Kaaplaas) & - & 1998/08/06 & KF483829 \\
\hline E080010_5 & 4 (Kaaplaas) & 2 & 2008/01/31 & KF483800 \\
\hline E080013_2 & 4 (Kaaplaas) & 2 & 2008/02/07 & KF483801 \\
\hline E080067- & 4 (Kaaplaas) & 2 & $2008 / 03 / 20$ & KF483804 \\
\hline E080129 & 4 (Kaaplaas) & 2 & $2008 / 04 / 10$ & KF483799 \\
\hline E080210_3 & 4 (Kaaplaas) & - & - & KF483810 \\
\hline E080229_2 & 4 (Kaaplaas) & - & - & KF483812 \\
\hline E080229_5 & 4 (Kaaplaas) & 3 & $2008 / 05 / 29$ & KF483813 \\
\hline E080260_10 & 4 (Kaaplaas) & 4 & $2008 / 07 / 17$ & KF483815 \\
\hline E100058 & 4 (Kaaplaas) & 3 & 2010/05/06 & KF483826 \\
\hline Reference strain & 5 (Kyalami) & 3 & $2002 / 01 / 28$ & KF483830 \\
\hline E090010_6 & 5 (Kyalami) & 5 & 2009/04/09 & KF483819 \\
\hline E090010_15 & 5 (Kyalami) & 3 & 2009/03/05 & KF483820 \\
\hline E090010_19 & 5 (Kyalami) & 3 & 2009/03/05 & KF483821 \\
\hline E090011 & 5 (Kyalami) & 4 & 2009/03/05 & KF483822 \\
\hline Reference strain & 6 (Potchefstroom) & - & $2002 / 02 / 25$ & KF483831 \\
\hline E100020 & 6 (Potchefstroom) & 4 & $2010 / 04 / 15$ & KF483825 \\
\hline Reference strain & $7(E 21 / 20)$ & 6 & $2003 / 05 / 23$ & KF483832 \\
\hline E080026 & $7(E 21 / 20)$ & 2 & $2008 / 02 / 21$ & KF483802 \\
\hline E080038 & $7(E 21 / 20)$ & 2 & 2009/03/07 & KF483803 \\
\hline E080070 & $7(E 21 / 20)$ & 7 & $2008 / 11 / 27$ & KF483805 \\
\hline E080089_3 & $7(E 21 / 20)$ & - & $2008 / 07 / 31$ & KF483806 \\
\hline E080146 & $7(E 21 / 20)$ & 9 & $2008 / 10 / 02$ & KF483808 \\
\hline E080181 & $7(E 21 / 20)$ & - & - & KF483809 \\
\hline E080186_1 & $7(E 21 / 20)$ & 8 & 2008/08/07 & KF483797 \\
\hline E080207 & $7(E 21 / 20)$ & - & - & KF483811 \\
\hline
\end{tabular}

- unknown passage number or isolation date. 
protocol (Supplementary data) run before elution of the RNA in $50 \mu \mathrm{l}$ Elution Buffer. The RNA was stored at $-20^{\circ} \mathrm{C}$ until used.

Extracted viral nucleic acid was denatured with $0.2 \mathrm{M}$ of methyl mercury (II) hydroxide (MMOH) and amplified with a one-step RT-PCR as described previously (Quan et al., 2008). The EEV S7 gene was amplified in two overlapping sections using primer EEV_VP7_F0007_0027 (ttt ggc caa caa gat gga tgc) with primer EEV_VP7_R0588_0609 (ctc gtg tac att gca aaa ggt c), and primer EEV_VP7_F0495_0516 (ttc agg tga gcc tta cgc cga a) with primer EEV_VP7_R1151_1175 (gta aca cgt ttg gcc tca gac gtt $\mathrm{t}$ ). An annealing temperature of $55^{\circ} \mathrm{C}$ was used and the PCR products visualized on a $1.5 \%$ agarose gel prepared with TAE buffer.

ExoSAP-IT (Affymetrix) was used according to the manufacturer's instructions to purify the PCR products. Sequencing reactions were prepared using a BigDye Terminator v3.1 cycle sequencing kit (Lifetech). Reactions consisted of $2 \mu \mathrm{l}$ Ready Reaction Premix, $1 \mu \mathrm{l}$ of BigDye Sequencing Buffer, 3.2 pmol primer and $5 \mu \mathrm{IPCR}$ products made up to $10 \mu \mathrm{l}$ in $\mathrm{H} 2 \mathrm{O}$. A standard sequencing protocol and sequencing product purification method using ethanol/NaOAc/EDTA precipitation (Lifetech) was followed. Samples were analysed with an ABI 3130xI Genetic Analyzer (Lifetech) using POP-7 polymer and a $36 \mathrm{~cm}$ capillary.

The Staden software package v1.5 (Staden, 1996; Staden et al., 2000) was used for sequence assembly, ClustalX v2.0.5 (Larkin et al., 2007) to align sequences and BioEdit Sequence Alignment Editor v7.0.9 software (Hall, 1999) to edit sequences. Conserved regions within the S7 gene were identified and used to design a real-time RT-PCR assay with a TaqMan ${ }^{\circledR}$ minor groove binder (MGB ${ }^{\text {TM }}$ ) hydrolysis probe, using Primer Express 3.0 software (Lifetech) and FastPCR software v6.1.47 (Kalendar et al., 2009).

\subsection{EEV real-time RT-PCR assay}

The nucleic acid from $50 \mu \mathrm{l}$ of blood was extracted using a MagMax ${ }^{\mathrm{TM}}-96$ Total RNA Isolation kit (Lifetech) according to the manufacturer's instructions, and a MagMax ${ }^{\mathrm{TM}}$ Express Particle Processor (Lifetech). Nucleic acid was eluted in $50 \mu$ l Elution Buffer.

Five $\mu \mathrm{l}$ RNA were added to $1 \mu \mathrm{l} 25 \mathrm{X}$ primer/probe mixture ( $400 \mathrm{nM} / 120 \mathrm{nM}$ final concentrations) and $4 \mu \mathrm{l}$ nuclease-free water. The probe was labeled with NED ${ }^{\mathrm{TM}}$ (Lifetech). The mixture was denatured by heating at $95^{\circ} \mathrm{C}$ for $1 \mathrm{~min}$ on a heatblock, and then cooled quickly on ice. VetMAX'M-Plus OneStep RT-PCR kit (Lifetech) reagents were added (12.5 $\mu$ l 2X RT-PCR buffer, $1.5 \mu$ l nuclease free water and $1 \mu$ lenzyme). The assay was performed following the manufacturer's recommendations on a StepOnePlus ${ }^{\text {TM }}$ Real-Time PCR System (Lifetech). Samples were classified as positive if the normalised fluorescence for the EEV assay exceeded a 0.1 threshold.

\subsection{Assay characteristics}

The assay was tested on tissue culture reference isolates of 24 serotypes of BTV, nine serotypes of AHSV and seven serotypes of EEV to determine the analytical specificity.

The efficiency of the assay was calculated using a ten-fold dilution series of blood (negative for EEV by virus isolation and RT-PCR and obtained from a clinically normal horse) spiked with EEV-2 obtained from tissue culture isolation (E118/12, $\left.10^{7.9} \mathrm{TCID}_{50} / \mathrm{ml}\right)$. The dilution series was tested five 
times in a single run. PCR efficiency were determined by the formula: PCR efficiency $(\%)=100 \times$ $\left(10^{1 / \text { slope }}-1\right)$.

A two-fold dilution series, consisting of six separate dilutions of EEV-spiked blood, was made to cover the non-linear range of the assay. Each dilution was extracted five times and each extract tested in five independent runs. The results of these analyses were used to calculate the $95 \%$ limit of detection (LOD) (input concentration giving a positive result in $95 \%$ of the replicates) by probit analysis.

The inter-run, intra-run and total standard deviations (SD) were calculated by the formulas: inter-run SD, standard deviation of the means of all runs; intra-run SD, mean of the standard deviations of all runs; total SD, standard deviation of all replicates. The total coefficient of variation (CV) was calculated by the formula: total $\mathrm{CV}=$ total $\mathrm{SD} /\left(\right.$ mean cycle threshold $\left(\mathrm{C}_{\mathrm{T}}\right)$-value of all replicates).

\section{Results}

\subsection{Primer design}

The EEV S7 genes of isolates all 7 serotypes of EEV was amplified in two overlapping segments 581 bp and 656 bp in length (Table 1).

The minimum percentage identity between isolates was $92.6 \%$ ( 82 differences out of 1123 nucleotides). These differences occurred between the reference EEV- 6 (Potchefstroom) strain, and EEV-5/EEV-7 isolates.

Conserved regions within the EEV S7 gene were identified (Figure 1a) and a 78 nucleotide TaqMan ${ }^{\circledR}$ MGB $^{\text {TM }}$ real-time RT-PCR developed at the $5^{\prime}$-end of the $\mathrm{S7}$ gene (Figure $1 \mathrm{~b}$ Table 2 and supplementary data). There was $100 \%$ identity of the forward primer and TaqMan ${ }^{\circledR}$ MGB $^{\mathrm{TM}}$ hydrolysis probe with all the EEV S7 sequences. A redundant reverse primer was designed as there was one nucleotide mismatch between the primer and the EEV S7 sequences. A BLAST analysis of the primers and probe showed specificity for EEV sequences.

An alignment of EEV, epizootic hemmorhagic disease virus (EHDV), BTV and AHSV S7 sequences showed very little identity between the viruses. Using FJ183391 as a reference, there was maximum identity of $72 \%$ over a $16 \%$ region of the EHDV S7 gene, $66 \%$ over a $18 \%$ region of the BTV S7 gene, and $66 \%$ over a $28 \%$ region of the AHSV S7gene.

\subsection{Assay characteristics}

The EEV real-time RT-PCR assay was specific, detecting all seven serotypes of EEV, but not AHSV nor BTV (Table 3).

The assay was linear in the range tested, i.e. $10^{2.9}-10^{6.9} \mathrm{TCID}_{50} / \mathrm{ml}$ blood. The efficiency of the assay was calculated to be $81 \%$ (Figure 2a).

The assay was sensitive, with a $95 \%$ LOD determined by probit analysis of $10^{2.9} \mathrm{TCID}_{50} / \mathrm{ml}$ blood (95 $\%$ confidence interval: $10^{2.7}-10^{3.3}$ ) (Figure $2 \mathrm{~b}$ ). This corresponded a $\mathrm{C}_{\mathrm{T}}$ of 38.42 . 
Table 2 : Real-time RT-PCR assay targeting the S7 (VP7) gene of EEV.

\begin{tabular}{llll}
\hline Name & Type & Position & Sequence (5'-3') \\
\hline EEV_VP7_F0028_0048 & Forward primer & $28-48$ & GAT AGC GGC TAG AGC CCT TTC \\
EEV_VP7_P0054_0072 & MGB $^{\text {TM }}$ probe & $54-72$ & TAA GAG CAT GTG TTA CTG C \\
EEV_VP7_R0085_0106 & Reverse primer & $85-106$ & AAC TTG AGG AGC CAT R*GT AGC T \\
\hline${ }^{*}$ R=A/G. & & &
\end{tabular}


Table 3 : Results of an EEV S7 (VP7) real-time RT-PCR assay tested on various reference orbiviruses. Samples were classified as negative if no fluoresence above the threshold (0.1) was detected within 35 cycles.

\begin{tabular}{|c|c|c|c|c|c|}
\hline Virus & Serotype & $\mathrm{C}_{\mathrm{T}}$-value & Passage number & Cell line & Date isolated \\
\hline AHSV & 1 & Negative & 4 & $\mathrm{BHK}$ & $2002 / 10$ \\
\hline AHSV & 2 & Negative & 4 & $\mathrm{BHK}$ & $2002 / 10$ \\
\hline AHSV & 3 & Negative & 5 & $\mathrm{BHK}$ & $2002 / 10$ \\
\hline AHSV & 4 & Negative & 4 & $\mathrm{BHK}$ & $2002 / 09$ \\
\hline AHSV & 5 & Negative & 4 & $\mathrm{BHK}$ & $2002 / 10$ \\
\hline AHSV & 6 & Negative & 3 & BHK & $2002 / 08$ \\
\hline AHSV & 7 & Negative & 5 & $\mathrm{BHK}$ & $2003 / 03 / 14$ \\
\hline AHSV & 8 & Negative & 5 & $\mathrm{BHK}$ & $2002 / 10$ \\
\hline AHSV & 9 & Negative & 5 & $\mathrm{BHK}$ & $2002 / 05 / 23$ \\
\hline BTV & 1 & Negative & - & - & $1998 / 01 / 28$ \\
\hline BTV & 2 & Negative & - & - & $1998 / 01 / 28$ \\
\hline BTV & 3 & Negative & - & - & $1998 / 01 / 28$ \\
\hline BTV & 4 & Negative & - & - & 1998/03/13 \\
\hline BTV & 5 & Negative & - & - & $1998 / 01 / 26$ \\
\hline BTV & 6 & Negative & - & - & $1998 / 01 / 26$ \\
\hline BTV & 7 & Negative & - & - & $1998 / 01 / 26$ \\
\hline BTV & 8 & Negative & - & - & 1998/07/09 \\
\hline BTV & 9 & Negative & - & - & $1997 / 11 / 21$ \\
\hline BTV & 10 & Negative & - & - & $1997 / 11 / 21$ \\
\hline BTV & 11 & Negative & - & - & 1998/07/09 \\
\hline BTV & 12 & Negative & - & - & 1998/07/09 \\
\hline BTV & 13 & Negative & - & - & $1998 / 07 / 20$ \\
\hline BTV & 14 & Negative & - & - & $1998 / 07 / 20$ \\
\hline BTV & 15 & Negative & - & - & $1998 / 07 / 20$ \\
\hline BTV & 16 & Negative & - & - & 1998/02/09 \\
\hline BTV & 17 & Negative & - & - & 1998/02/09 \\
\hline BTV & 18 & Negative & - & - & $1998 / 02 / 10$ \\
\hline BTV & 19 & Negative & - & - & 1998/02/10 \\
\hline BTV & 20 & Negative & - & - & $1998 / 02 / 16$ \\
\hline BTV & 21 & Negative & - & - & $1998 / 02 / 16$ \\
\hline BTV & 22 & Negative & - & - & 1998/10/08 \\
\hline BTV & 23 & Negative & - & - & 1998/02/17 \\
\hline BTV & 24 & Negative & - & - & $1998 / 03 / 13$ \\
\hline EEV & 1 & 21.57 & 1 & $\mathrm{BHK}$ & $2004 / 11 / 26$ \\
\hline EEV & 2 & 21.54 & 3 & $\mathrm{BHK}$ & 2002/09/09 \\
\hline EEV & 3 & 21.07 & - & - & 1998/08/06 \\
\hline EEV & 4 & 19.64 & - & - & 1998/08/06 \\
\hline EEV & 5 & 21.28 & 2 & $\mathrm{BHK}$ & $2002 / 01 / 28$ \\
\hline EEV & 6 & 20.79 & - & - & $2002 / 02 / 25$ \\
\hline EEV & 7 & 22.59 & 6 & BHK & $2003 / 05 / 23$ \\
\hline
\end{tabular}

AHSV - African horse sickness virus, BHK - baby hamster kidney, BTV - bluetongue virus, $\mathrm{C}_{\mathrm{T}}$ cycle threshold, EEV - equine encephalosis virus, dash indicates unknown. 
Figure 1a

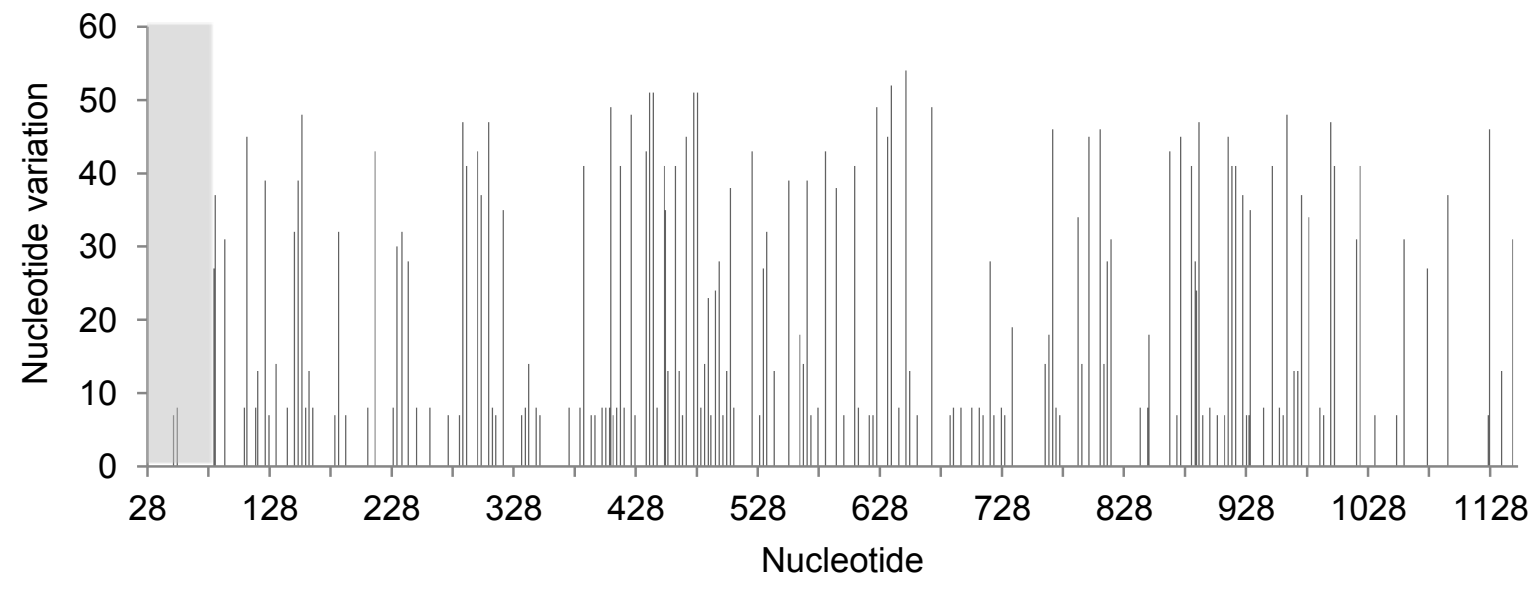

Figure 1b
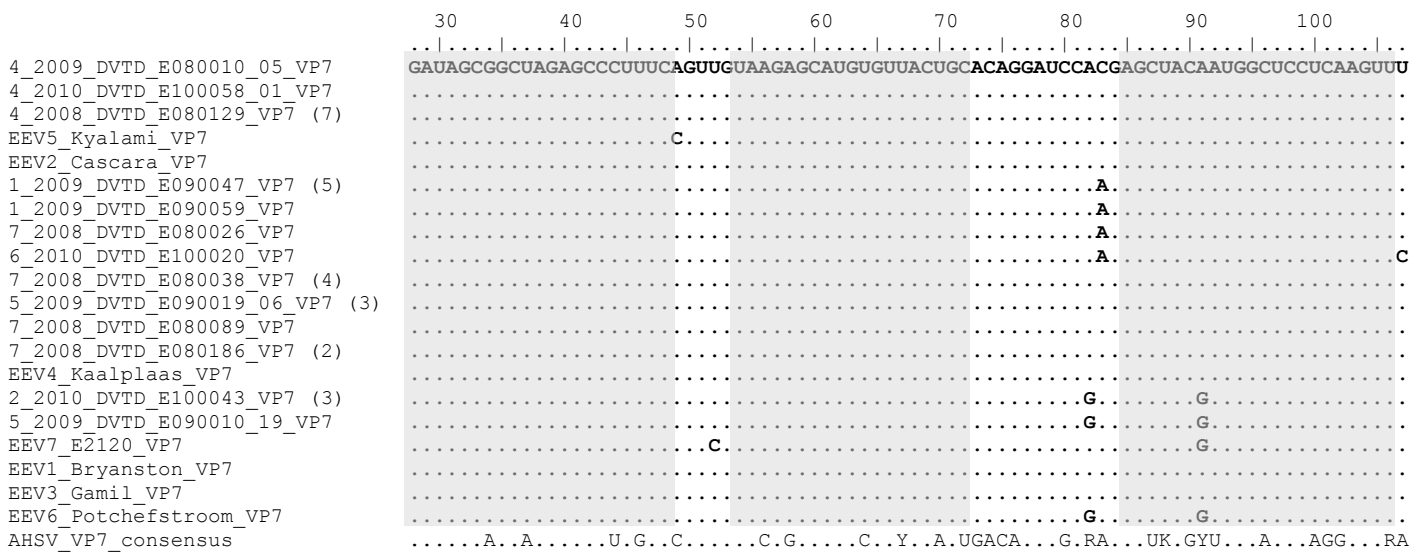

Fig. 1. (a) Plot of conservation sites on the VP7 gene, calculated using quality scores in ClustalX. No column at a nucleotide position indicates $100 \%$ conservation, the higher the column, the greater the nucleotide variation at that site. Genbank accession number FJ183391 was used for nucleotide numbering. The conserved region where the assay was developed is indicated by a grey block. (b) Detail of the grey block in 1a. EEV S7 (VP7) gene sequences and an African horse sickness virus (AHSV) S7 (VP7) consensus sequence (Quan et al., 2010) included for comparison. Dots indicate identity and letters differences with the first sequence in the group. Identical sequences are represented only once in the figure and the number of identical sequences are indicated in brackets after the name of a random sequence in the group. The location of the real-time RT-PCR assay primers and probe are indicated by grey shaded boxes. 
Figure 2a

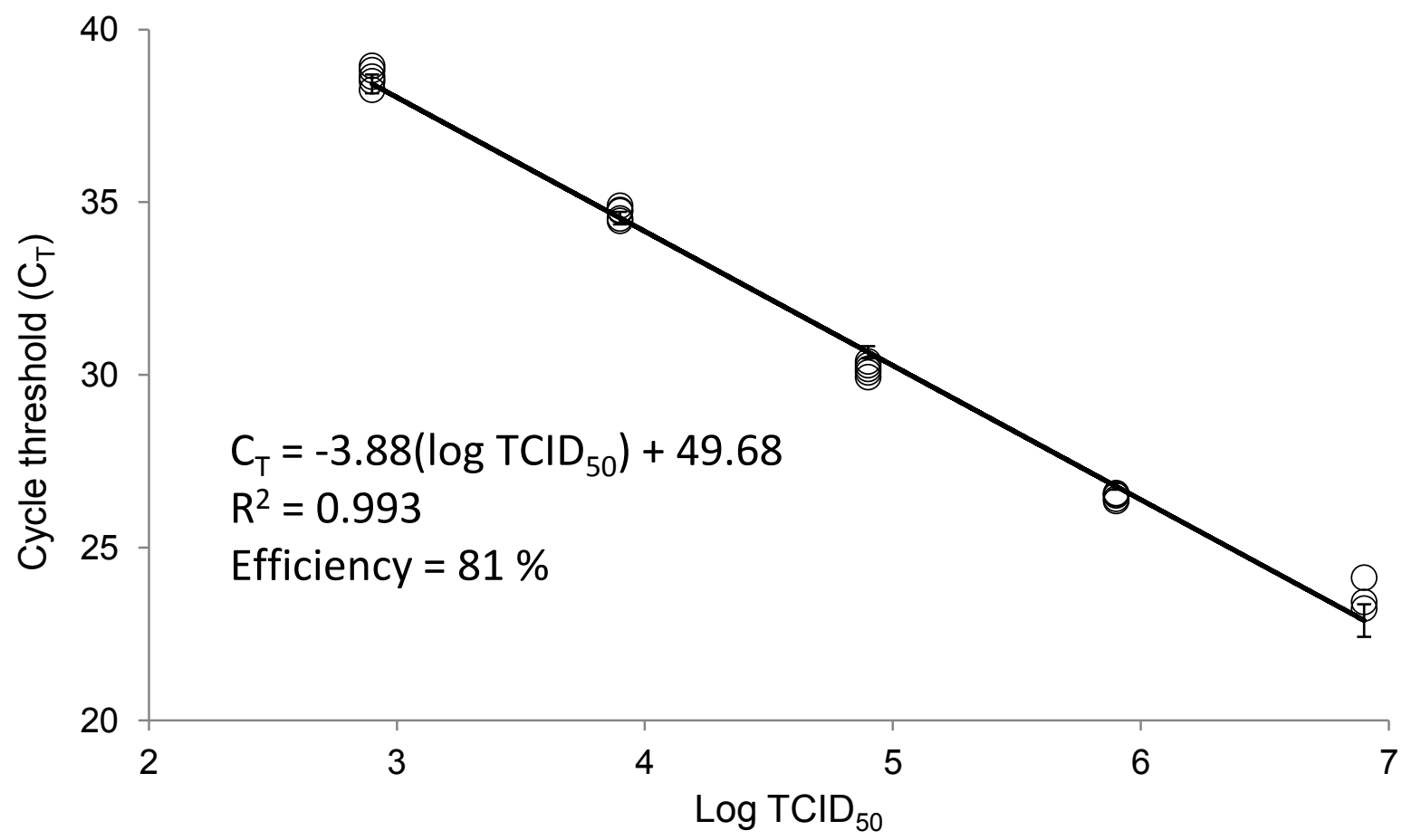

Figure $\mathbf{2 b}$

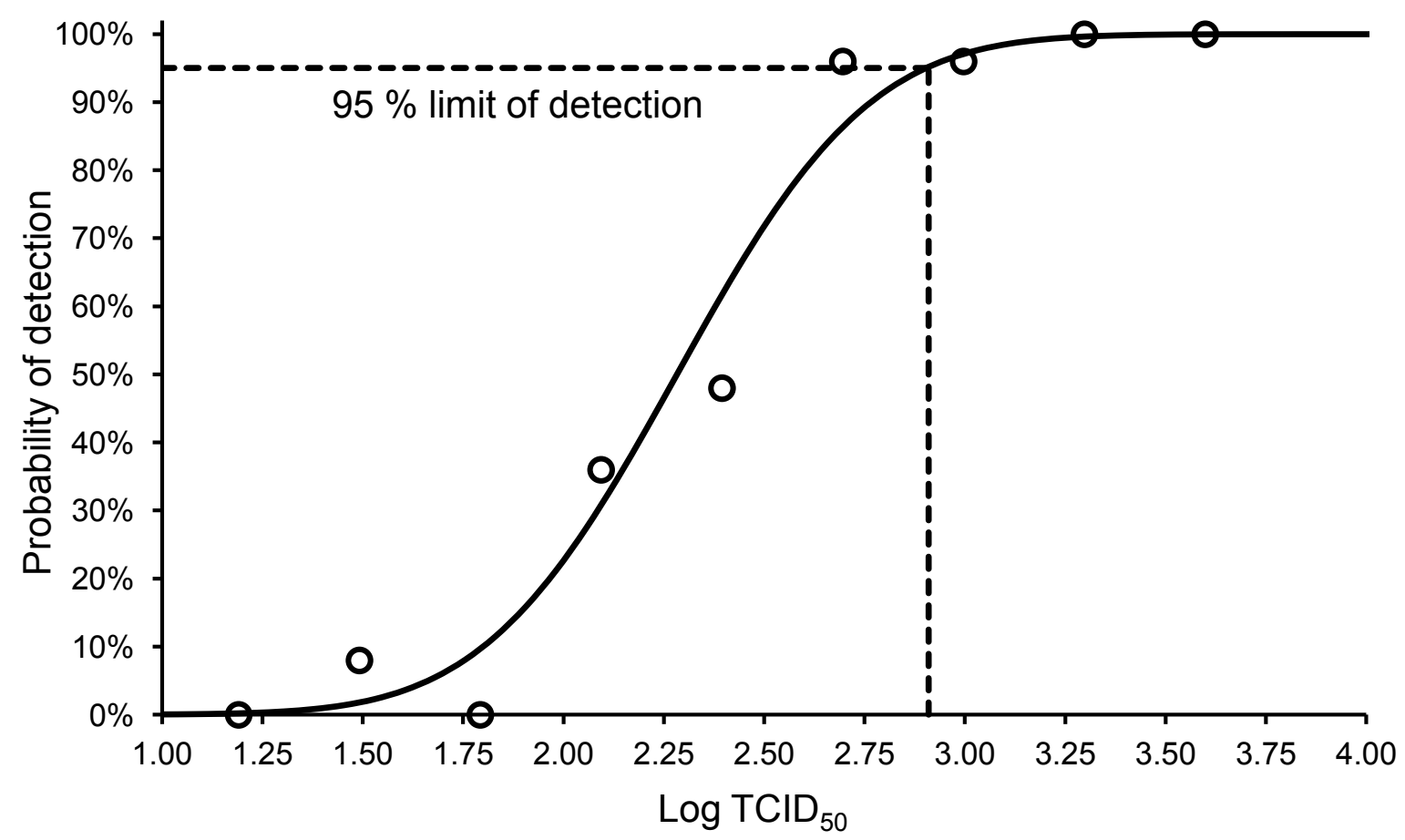

Fig. 2. (a) Regression \pm standard deviation of a ten-fold dilution series of blood spiked with EEV obtained from tissue culture isolation. Each dilution was repeated five times in a run. (b) A twofold dilution series of EEV-spiked blood covering the non-linear range of the EEV assay. Circles represent the detection probability from 25 replicates (five separate runs with five replicates per run) and the dotted line indicates the $95 \%$ limit of diftection $\left(10^{2.91} \mathrm{TCID}_{50} / \mathrm{ml}\right.$ blood. 
Table 4 : Inter- and intra-run variation for six two-fold dilutions of EEV infected horse blood. The dashed line between -3.00 and $-2.70 \log 10$ dilution represents the limit of detection.

\begin{tabular}{|c|c|c|c|c|c|}
\hline \multirow{2}{*}{$\begin{array}{l}\text { Samples } \\
\log _{10} \text { dilution }\end{array}$} & \multicolumn{5}{|c|}{ Results $\left(\mathrm{C}_{\mathrm{T}}\right)$} \\
\hline & Mean & Inter-run SD & Intra-run SD & Total SD & Total CV \\
\hline 3.60 & 34.87 & 2.07 & 0.42 & 1.94 & 0.056 \\
\hline 3.30 & 35.73 & 0.78 & 0.34 & 0.78 & 0.022 \\
\hline 3.00 & 36.91 & 2.06 & 0.32 & 1.89 & 0.051 \\
\hline 2.70 & 37.73 & 1.85 & 0.31 & 1.72 & 0.046 \\
\hline 2.39 & 38.43 & 0.98 & 0.47 & 0.79 & 0.020 \\
\hline 2.09 & 39.45 & 0.16 & 0.45 & 0.44 & 0.011 \\
\hline
\end{tabular}

$\mathrm{C}_{\mathrm{T}}$ - cycle threshold, SD - standard deviation, $\mathrm{CV}$ - coefficient of variation 
Both intra- and inter-run standard deviations (SD) were low with maxima at $0.47 \mathrm{C}_{\mathrm{T}}$ and $2.07 \mathrm{C}_{\mathrm{T}}$, respectively (Table 4). The coefficient of variation (CV) ranged from $1.1 \%$ to $5.6 \%$, indicating low variation between different repetitions and different runs.

\section{Discussion}

Equine encephalosis is a generally a mild or subclinical disease of horses. Although EEV is occasionally isolated from organs of dead horses it is not a World Organisation for Animal Health (OIE) listed disease. It does, however, play a very important role as a differential diagnosis for mild cases of AHS, a high impact disease listed by the OIE. Both diseases can present with similar clinical signs, are caused by (Orbiviruses) and are seasonal, with a peak incidence at the end of summer, when Culicoides midge numbers are at their highest. It is imperative to distinguish between AHS and equine encephalosis, as the control measures and consequences differ vastly. In South Africa, AHS is a controlled notifiable disease, whilst equine encephalosis is not.

The S7 gene of EEV is translated into the VP7 protein, which makes up the outer layer of the inner capsid of the EEV. The inner capsid is covered by the outer capsid, a layer of proteins composed of VP2 and VP5. VP7 has limited exposure on the surface of the intact virion, but is a highly immunedominant antigen and antibodies against VP7 can be detected by an ELISA (Crafford et al., 2003).

The aim of this study was to develop a specific, sensitive, rapid and robust real-time RT-PCR assay for the detection of EEV and the $\mathrm{S} 7$ gene was selected as a target as it is highly conserved among serotypes and serogroups (Bremer et al., 1990; Mertens et al., 1984). As only two epitopes of the S7 gene are expressed on the surface of the virus (Anthony et al., 2007), the mutation rate of the gene due to immune pressure may be quite low.

The sequences of $38 \mathrm{EEV}$ isolates, including all seven serotypes of EEV, as well as all the reference strains of EEV were obtained. The S7 gene was relatively well conserved with $92.6-100 \%$ identity between the 38 isolates sequenced. The terminal ends of the 57 gene were more conserved than the middle region, similar to AHSV VP7 and NS2 sequences (Quan et al., 2010). The conserved region at the $5^{\prime}$ end of the $\mathrm{S7}$ gene (115 nucleotides) was longer than the $3^{\prime}$ end, so the real-time RT-PCR assay was designed to target the former region.

The TaqMan ${ }^{\circledR}$ MGB ${ }^{\text {TM }}$ RT-PCR assay developed for detection of EEV nucleic acid is specific and quick to perform, as it does not require visualization of the PCR products by electrophoresis. The elimination of this step saves laboratory equipment and reagents, but require a more advanced and expensive real-time thermocycler which is not available in every diagnostic laboratory. The real-time reagents are much more expensive than those used in conventional PCR, but the assay provides a convenient way of obtaining reproducible results within a short time.

The assay can be used to detect rapidly and reliably any of the EEV strains that were tested in cell or tissue culture and to distinguish EEV from AHSV. It will be useful in endemic countries where both viruses are circulating to ensure that correct control strategies are used.

As the assay was planned to be used in a multiplex format, the testing was done with a probe labeled with NED ${ }^{\mathrm{TM}}$ dye. On the StepOnePlus Real-Time PCR ${ }^{\mathrm{TM}}$ system, the efficiency of the assay appears to vary with the dye that is used. The efficiency of the same assay with 6-FAM or VIC ${ }^{\circledR}$ 
appears to be much higher than with the NED ${ }^{\mathrm{TM}}$ dye (personal observation). This may explain why the efficiency of the assay was not higher and closer to $100 \%$.

The $95 \%$ LOD of the assay was $10^{2.9} \mathrm{TCID}_{50} / \mathrm{ml}$ blood. There are no other published real-time RT-PCR EEV assays to compare with, but assays for AHSV have reported an end-point LOD of $10^{1.5}$ (Agüero at el., 2008), $10^{-0.90}$ (Fernández-Pinero et al., 2008) and $10^{-0.08}$ (Rodriguez-Sanchez et al., 2008) $\mathrm{TCID}_{50} / \mathrm{ml}$. As these are end-point LODs, the assay appears to compare favourably. Monaco et al., (2011) reported a $95 \%$ LOD of $10^{0.33} \mathrm{TCID}_{50} / \mathrm{ml}$ for an AHSV assay, which is more sensitive than the EEV assay. It is possible that the sensitivity of the EEV could be increased with the use of different dyes, e.g. FAM or VIC ${ }^{\circledR}$ on the probes.

The results described in this study contribute to the improvement of the available techniques for the detection of EEV antigen and/or antibodies against EEV. So far, the only group-specific EEV assay is the indirect sandwich ELISA for the detection of EEV antigen (Crafford et al., 2003). The assay takes a day to obtain results. To date, there is no publishedmolecular assay for EEV and this is the first study to describe a real-time RT-PCR assay for the detection of EEV.

\section{Acknowledgements}

We would like to thank Dr Victor Bagla for useful comments on the manuscript. This research was funded by the Equine Research Centre of the University of Pretoria, Racing South Africa (Pty) Ltd, The Mary Slack and Daughters Foundation and the National Research Foundation, South Africa.

\section{References}

Agüero, M., Gómez-Tejedor, C., Angeles, C.M., Rubio, C., Romero, E., Jiménez-Clavero, A., 2008. Real-time fluorogenic reverse transcription polymerase chain reaction assay for detection of African horse sickness virus. J. Vet. Diagn. Invest. 20, 325-328.

Aharonson-Raz, K., Steinman, A., Bumbarov, V., Maan, S., Maan, N.S., Nomikou, K., Batten, D., Potgieter, C., Gottlieb, Y., Mertens, P., Klement, E., 2011. Isolation and phylogenetic grouping of equine encephalosis virus in Israel. Emerg. Infect. Dis. 17(10), 1883-1886. doi:

10.3201/eid1710.110350.

Anthony, S., Jones, H., Darpel, K.E., Elliott, H., Maan, S., Samuel, A., Mellor, P.S., Mertens, P.P., 2007. A duplex RT-PCR assay for detection of genome segment 7 (VP7 gene) from 24 BTV serotypes. J. Virol. Methods 141, 188-197.

Barnard, B.J., 1997. Antibodies against some viruses of domestic animals in southern African wild animals. Onderstepoort J. Vet. Res. 64, 95-110.

Belhouchet, M., Mohd Jaafar, F., Firth, A.E., Grimes, J.M., Mertens, P.P., Attoui, H., 2011 Detection of a fourth orbivirus non-structural protein. PLoS One 6(10):e25697. doi:

10.1371/journal.pone.0025697.

Bremer, C.W., Huismans, H., Van Dijk, A.A., 1990. Characterization and cloning of the African horsesickness virus genome. J. Gen. Virol. 71(Pt 4), 793-799. 
Crafford, J.E., Guthrie, A.J., Van Vuuren, M., Mertens, P.P.C., Burroughs, J.N., Howell, P.G., Hamblin, C., 2003. A group-specific, indirect sandwich ELISA for the detection of equine encephalosis virus antigen. J. Virol. Methods 112, 129-135.

Erasmus, B.J., Adelaar, T.F., Smit, J.D., 1970. The isolation and characterization of equine encephalosis virus. Bull World Health Organ 74, 781-789.

Fernández-Pinero, J., Fernández-Pacheco, P., Rodríguez, B., Sotelo, E., Robles, A., Arias, M., SánchezVizcaíno, J.M., 2009. Rapid and sensitive detection of African horse sickness virus by real-time PCR. Res. Vet. Sci. 86 (2), 353-358.

Firth, A.E., 2008. Bioinformatic analysis suggests that the Orbivirus VP6 cistron encodes an overlapping gene. Virol. J. 5:48. doi:10.1186/1743-422X-5-48.

Gorman, B.M., Taylor, J., Walker, P.J., 1983. Orbivirus, in: Joklik, W.K. (Ed.), The Reoviridae. Plenum Press, New York, pp. 287-357.

Hall, T.A., 1999. BioEdit: A user-friendly biological sequence alignment editor and analysis program for windows 95/98/NT. Nucl. Acids Symp. Ser. 41, 95-98.

Howell, P.G., Groenewald, D., Visage, C.W., Bosman, A.M., Coetzer, J.A., Guthrie, A.J., 2002.The classification of seven serotypes of equine encephalosis virus and the prevalence of homologous antibody in horses in South Africa. Onderstepoort J. Vet. Res. 69, 79-93.

Howell, P.G., Guthrie, A.J., Coetzer, J.A.W., 2004. Equine encephalosis, in: Coetzer, J.A.W., Tustin, R. (Eds.), Infectious diseases of livestock. 2nd edition. Oxford University Press, Cape Town, pp. 12471251.

Kalendar, R., Lee, D., Schulman, A.H., 2009. FastPCR software for PCR primer and probe design and repeat search. Genes, genomes and genomics 3(1), 1-14.

Larkin, M.A., Blackshields, G., Brown, N.P., Chenna, R., McGettigan, P.A., McWilliam, H., Valentin, F., Wallace, I.M., Wilm, A., Lopez, R., Thompson, J.D., Gibson, T.J., Higgins, D.G., 2007. Clustal W and Clustal X version 2.0. Bioinformatics 23, 2947-2948.

Mertens, P.P., Brown, F., Sangar, D.V., 1984. Assignment of the genome segments of bluetongue virus type 1 to the proteins which they encode. Virology 135, 207-217.

Mildenberg, Z., Westcott, D., Bellaiche, M., Dastjerdi, A., Steinbach, F., Drew, T., 2009. Equine encephalosis in Isreal. Transbound. Emerg. Dis. 56(8), 291. doi: 10.1111/j.1865-

1682.2009.01087_1.x.

Monaco, F., Polci, A., Lelli, R., Pinoni, C., Di Mattia, T., Mbulu, R.S., Scacchia, M., Savini, G., 2011. A new duplex real-time RT-PCR assay for sensitive and specific detection of African horse sickness virus. Mol. Cell. Probes 25, 87-93.

Oura, C.A., Batten, C.A., Ivens, P.A., Balcha, M., Alhassan, A., Gizaw, D., Elharrak, M., Jallow, D.B., Sahle, M., Maan, N., Mertens, P.C., Maan, S., 2012. Equine encephalosis virus: evidence for circulation beyond southern Africa. Epidemiol. Infect. 140(11), 1982-1986. 
Paweska, J.T., Gerdes, G.H., Woods, P.S., Williams, R., 1999. Equine encephalosis in southern Africa: current situation, in: Wernery, U., Wade, J.F., Mumford, J.A. et al (Eds.), Equine infectious diseases. Newmarket: R \& W., Newmarket, pp. 303-305.

Paweska, J.T., Venter, G.J., 2004. Vector competence of culicoides species and the seroprevalence of homologous neutralizing antibody in horses for six serotypes of equine encephalosis virus (EEV) in South Africa. Med. Vet. Entomol. 18, 398-407.

Quan, M., Lourens, C.W., MacLachlan, N.J., Gardner, I.A., Guthrie, A.J., 2010. Development and optimisation of a duplex real-time reverse transcription quantitative PCR assay targeting the VP7 and NS2 genes of African horse sickness virus. J. Virol. Methods 167, 45-52. doi: 10.1016/j.jviromet.2010.03.009.

Quan, M., van Vuuren, M., Howell, P.G., Groenewald, D., Guthrie, A.J., 2008. Molecular epidemiology of the African horse sickness virus S10 gene. J. Gen. Virol. 89, 11591168. doi: 10.1099/vir.0.83502-0.

Ratinier, M., Caporale, M., Golder, M., Franzoni, G., Allan, K., Nunes, S.F., Armezzani, A., Bayoumy, A., Rixon, F., Shaw, A., Palmarini, M., 2011. Identification and characterization of a novel non-structural protein of bluetongue virus. PLoS Pathog. 7(12):e1002477. doi: 10.1371/journal.ppat.1002477.

Rodriguez-Sanchez, B., Fernandez-Pinero, J., Sailleau, C., Zientara, S., Belak, S., Arias, M., Sanchez-Vizcaino, J.M., 2008. Novel gel-based and real-time PCR assays for the improved detection of African horse sickness virus. J. Virol. Methods 151, 87-94.

Staden, R., 1996. The Staden sequence analysis package. Mol. Biotechnol. 5, 233-241.

Staden, R., Beal, K.F., Bonfield, J.K., 2000. The Staden package, 1998. Methods Mol. Biol. 47 132, 115-130.

Theiler, A., 1910. Notes on a fever in horse simulating 1 horse-sickness. Transvaal Agricultural 2 J. 8(32), 581-686.

Theodoridis, A., Nevill, E.M., Els, H.J., Boshoff, S.T., 1979. Viruses isolated from Culicoides midges in South Africa during unsuccessful attempts to isolate bovine ephemeral fever virus. Onderstepoort J. Vet. Res. 46, 191-198.

Venter, G.J., Paweska, J.T., Williams, R., Nevill, E.M., 1999. Prevalence of antibodies against African horse sickness and equine encephalosis viruses in donkeys in southern Africa, in Wernery, U., Wade, J.F., Mumford, J.A., Kaaden, O.R. (Eds.), Proceedings 8th International Conference on Equine Infectious Diseases, 23-26 March 1998, pp 299-302.

Williams, R., du Plessis, D.H., van Wyngaardt, W., 1993. Group-reactive ELISAs for detecting antibodies to African horse sickness and equine encephalosis viruses in horses, donkey and zebra sera. J. Vet. Diagn. Invest. 5, 3-7. 
Customized protocol for the MagMax ${ }^{\mathrm{TM}}$ Express Particle Processor (Lifetech) for RNA extraction.

\section{[ PROTOCOL PROPERTIES ]}

Name $=$ AM1830_Mod3

Protocol template version $=2.6 .0$

Instrument type $=$ KingFisher

Creator $=$ mquan

Created $=30 / 9 / 2009$ 9:31:36

Description $=$ RNA isolation from whole blood.

Kit $=$ MagMAX-96 viral RNA Isolation Kit , AM1836

Plate layouts $=$ Default

\section{[ PLATE LAYOUTS ]}

\section{Default}

Plate type $=$ KingFisher plate $200 \mathrm{ul}$

Plate change message $=$ Change Default

A:

- volume $=20$, name $=$ Bead Mix (10 ul RNA binding beads, $10 \mathrm{ul} \mathrm{Lysis/Binding} \mathrm{Enhancer})$

- volume $=50$, name $=$ Whole blood

- volume = 130, name = 65 ul Lysis/Binding Solution, 1 ul Carrier RNA, 2 ul Xeno RNA, 65 ul

Isopropanol

B:

- volume $=150$, name $=$ Wash Solution 1

C:

- volume $=150$, name $=$ Wash Solution 1

D:

- volume $=150$, name $=$ Wash Solution 2

E:

- volume $=150$, name $=$ Wash Solution 2

F:

- volume $=50$, name $=$ Elution Buffer

G:

- EMPTY

$\mathrm{H}$ :

- EMPTY

\section{[ STEPS ]}

BIND

Step parameters

- Name = Lysis Binding 5 min

- Well = A, Default

Beginning of step:

- No Action = Yes

Bind parameters: 
- Bind time $=5 \min 0 \mathrm{~s}$, speed $=$ Fast dual $\mathrm{mix}$

End of step:

- Collect beads $=$ Yes, count $=5$

WASH

Step parameters

- Name = 1st Wash I $1 \mathrm{~min}$

- Well = B, Default

Beginning of step:

- Release $=$ Yes, time $=0$ s, speed $=$ Fast

Wash parameters:

- Wash time $=1 \mathrm{~min} 0 \mathrm{~s}$, speed $=$ Fast

End of step:

- Collect beads $=$ Yes, count $=3$

WASH

Step parameters

- Name = 2nd Wash I 1 min

- Well = C, Default

Beginning of step:

- Release $=$ Yes, time $=0$ s, speed $=$ Fast

Wash parameters:

- Wash time $=1 \mathrm{~min} 0 \mathrm{~s}$, speed $=$ Fast

End of step:

- Collect beads $=$ Yes, count $=3$

\section{WASH}

Step parameters

- Name = 1st Wash II 1 min

- Well = D, Default

Beginning of step:

- Release $=$ Yes, time $=0$ s, speed $=$ Fast

Wash parameters:

- Wash time $=1 \mathrm{~min} 0 \mathrm{~s}$, speed $=$ Fast

End of step:

- Collect beads $=$ Yes, count $=2$

\section{WASH}

Step parameters

- Name = 2nd Wash II 1 min

- Well = E, Default

Beginning of step:

- Release $=$ Yes, time $=0$ s, speed $=$ Fast

Wash parameters:

- Wash time $=1 \mathrm{~min} 0 \mathrm{~s}$, speed $=$ Fast

End of step: 
- Collect beads $=$ Yes, count $=2$

DRY

Step parameters

- Name = Dry $1 \mathrm{~min}$

- Well = E, Default

- Dry time $=1 \mathrm{~min} 0 \mathrm{~s}$

- Tip position = Outside well

\section{ELUTION}

\section{Step parameters}

- Name = Elution $3 \mathrm{~min}$

- Well = F, Default

\section{Beginning of step:}

- Release $=$ Yes, time $=0$ s, speed $=$ Fast

\section{Elution parameters:}

- Elution time $=3 \mathrm{~min} 0 \mathrm{~s}$, speed $=$ Bottom medium

Pause parameters:

- Pause for manual handling $=$ No

Remove beads:

- Remove beads $=$ Yes, collect count $=5$, disposal well $=B$ 
4_2009_DVTD_E080010_05_VP7

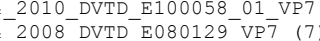
EĒV5_KYalamì_VP7

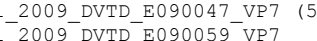

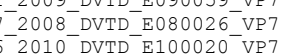

2008 DVTDEE080038-VP7 (4) 52009-DVTD_E090019-06 VP7 (3) 2008 DVTD E080186-VP7 (2)

2.2010_DVTD_E100043_VP7 (3)
5 2009DVTDEE90010_19_VP7 EEV1 Bryanston

EEV6_Potchéfstroom_VP

4_2009_DVTD_E080010_05_VP7 4-2010-DVTD_E100058-01-VP7 EEV5_KYalami_VP7

20009_DVTD E E090047_VP7 (5) -2009-DVTD_E090059-VP7
$-2008^{-}$DVTDEE080026-VP7

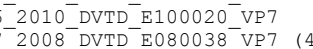

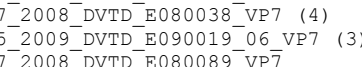
$\begin{array}{ll} & \end{array}$

T. Kaalplaas VP7

5 2009-DVTDEE090010_19_VP7

EEV7_E2120_VP7

EEV1-Bryanston_VP7
EEVI-Gami1 VP7

EEV6_Potchefstroom_VP7

4_2009_DVTD_E080010 05_VP7 DVTDE100058-01-VP7 EEV5_Kyalami_VP7

2009_DVTDEE090047_VP7 (5) 12009_DVTD_E090059_VP7

7-2008_DVTD_E080026_VP7

2008_DVTD_E080038_VP7 (4)

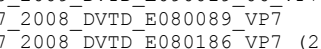

7-2008_DVTD_E08018

2010_DVTDE1010043_VP7 (3)

EEV7_E22120_VP7

EEVI_Gami1_VPT

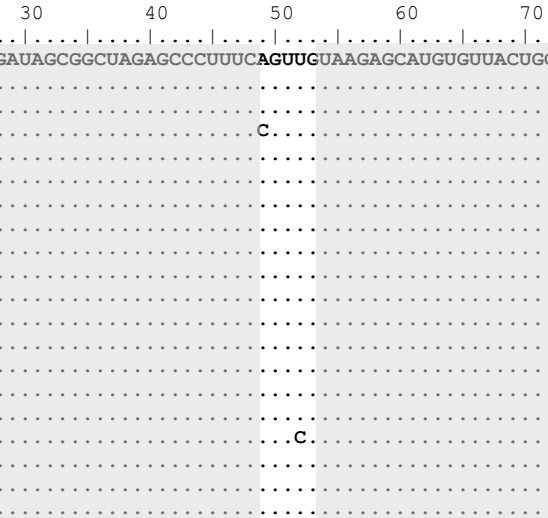

$90 \quad 100$

110

120

130

140

$150 \quad 160 \quad 170$
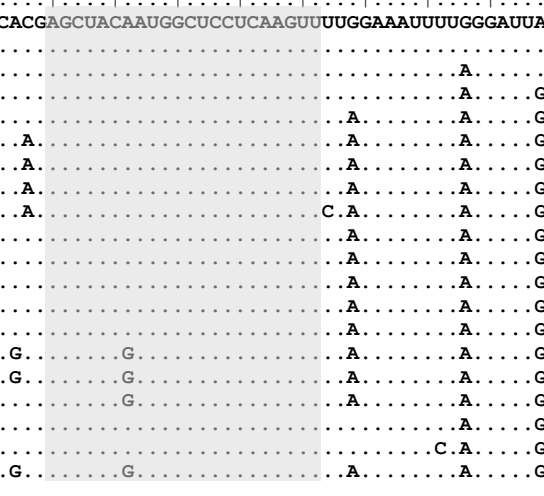

c.c.G.

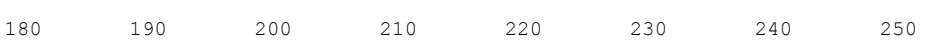

$260 \quad 270$

290

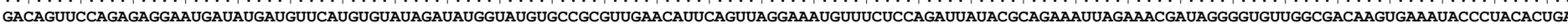

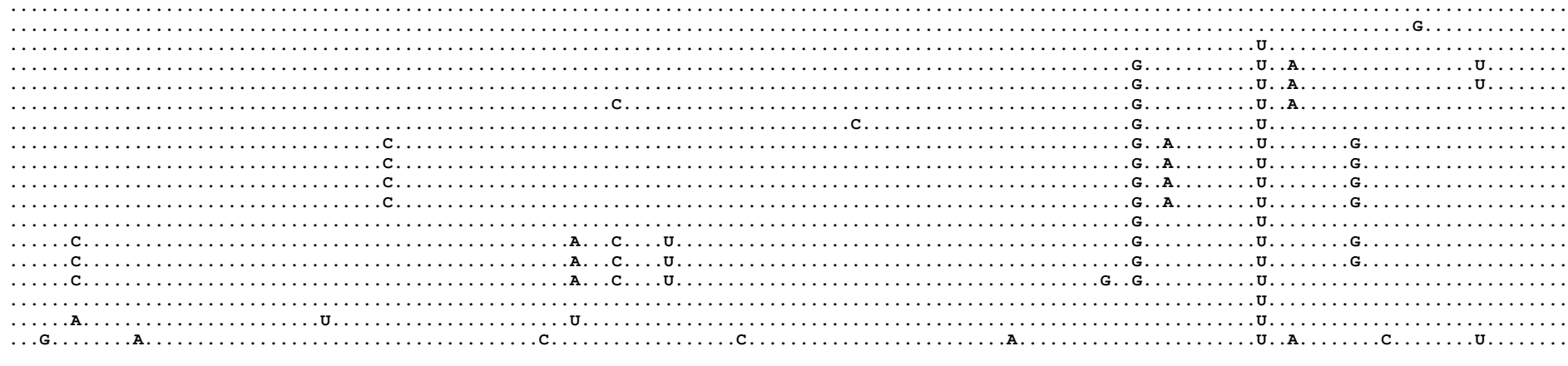
330
$340 \quad 350 \quad 36$
$380 \quad 390$
$400 \quad 410$
420
440
$450 \quad 460 \quad 470$

UGAGGCGAUUAACGCGAUGUGAGGUGA.
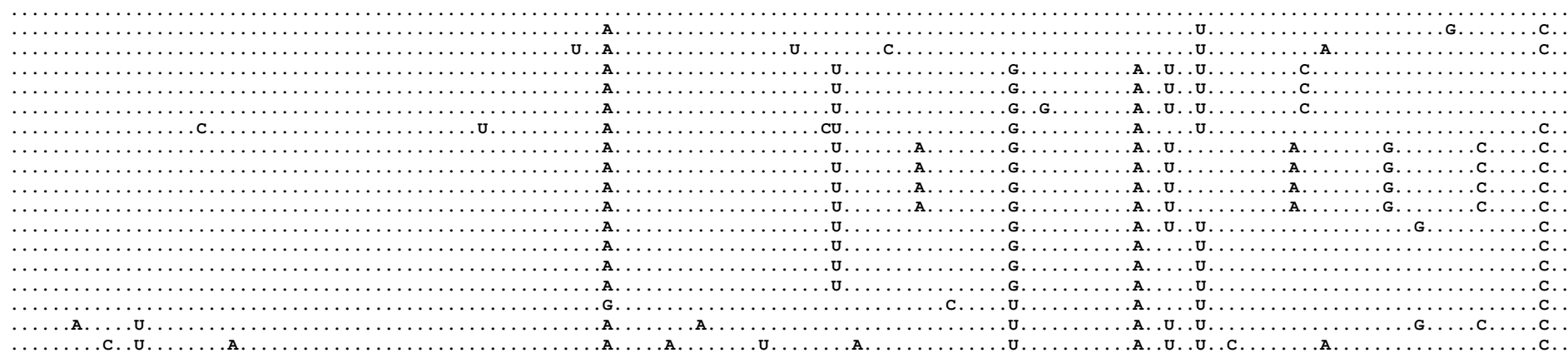
CACUGAUUCCAACACUAUUCAGGUGAGCCUUACGCCGAACAGUGCUGCGCAAGUCAACGGCGCUAUGACGCGGCAAGGUGUGGAGCUCGUGCAGUUAUUUUUUGGUAUGGAGACCUUUUGCAAUGUACACAAGUCAGGCGGGAGCAGCCGU

42009-DVTD_E080010_05_VP 2008 DVTDE080129-VP7 (7) EEVE5 KŸalamí VP7

2009_DVTD_E090047_VP7 (5) - 2009_DVTDEE90059_VP7 6 2010 DVTDE100020-VP7

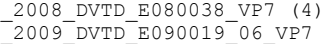

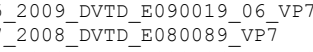
EV4 Käalplàas VP7

_2010_DVTD_E100043_VP7 (3)

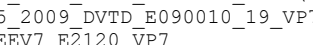

EVV6-Potch

2009 DVTD_E080010_05_VP7 4 2010DVTDE100058-01-VP7 EEV5_KYalami_VP7

2009_DVTD_E090047_VP7 (5) 2009_DVTD_E090059-VP7

6010_DVTDEE100020_VP7 $\begin{array}{ll} & \end{array}$ -2008_DVTD_E080089_VP7 (3) $20 \overline{10}$ DVTD E100043 52009_DVTD_E090010_19_VP7

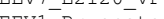

EEV1_Bryanston_VP7

EEV6-Potchefstroom_VP7

4_2009_DVTD_E080010_05_VP 2010-DVTDE100058-01-VP 2008_DVTD_E080129_VP7 (7) EVV5_Kyalami_VP7

1_2009_DVTD_E090047 VP7 (5)

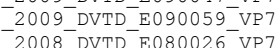

- $2010^{-D V T D E}$ E100020-VP7

7. $2008^{-}$DVTD E080089-VP
DV FEV4 Ka DVIDLE08018

_2010_DVTD_E100043_VP7 (३)

2009 DVTD E090010 19 VP7

EEV1_Bryanston_VP7

EEV3-Gamil_VP
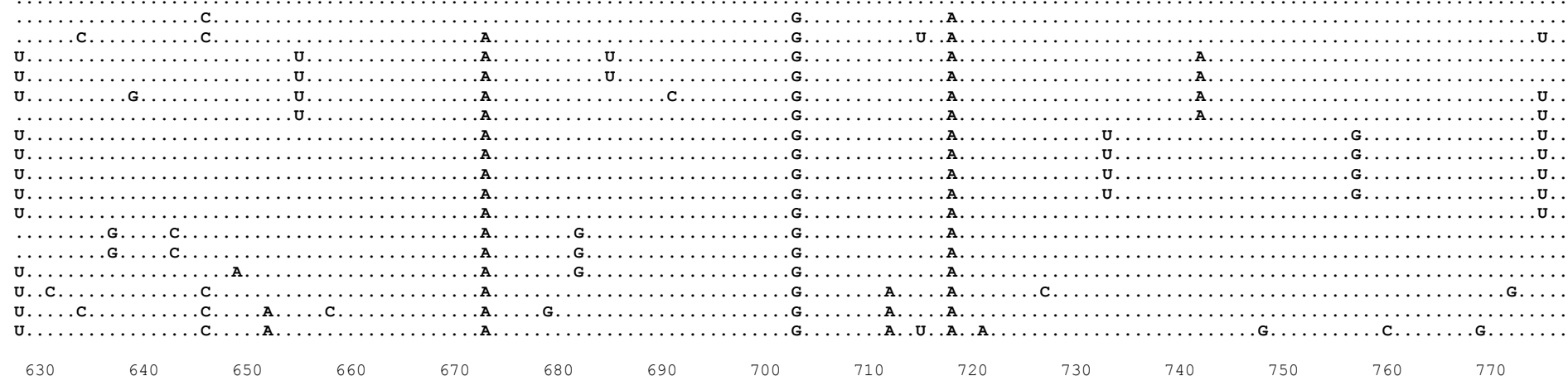

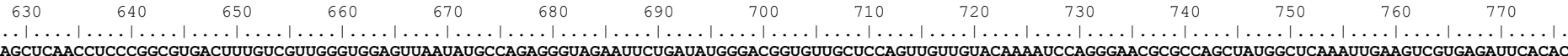

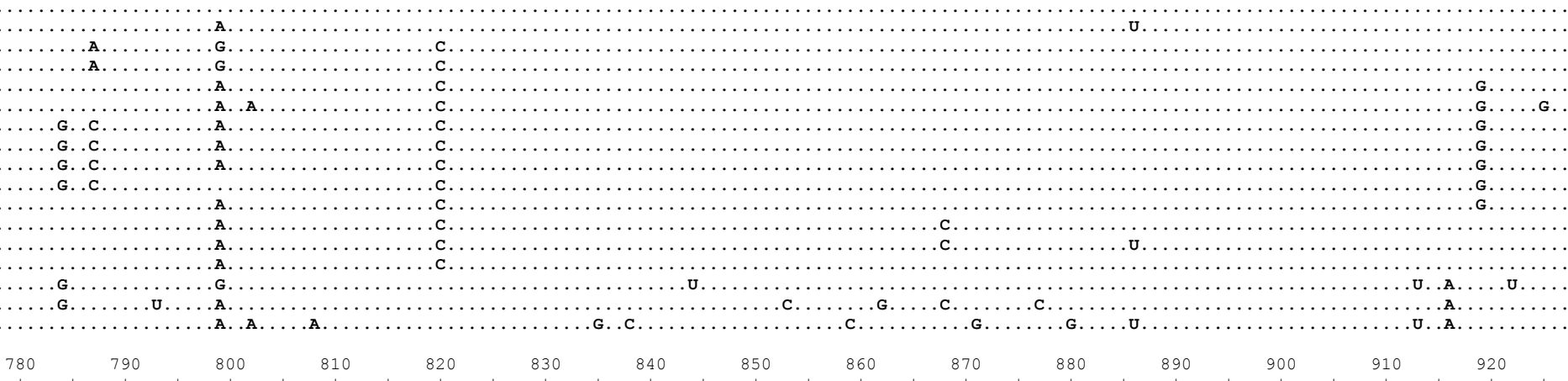

GCUCCUACACUCAUAUGAGACGGUUCCAGAAACCGUGAGAUAUGCUAGAUGCUACUCAUUCCUUAGUGUACGUGGCACACCUCCGAUCAGCUAUUCUGAGGUCCUUAGGAAUGCUUCCAGUGCACCAGUCCGCCUAUCCACCGAC

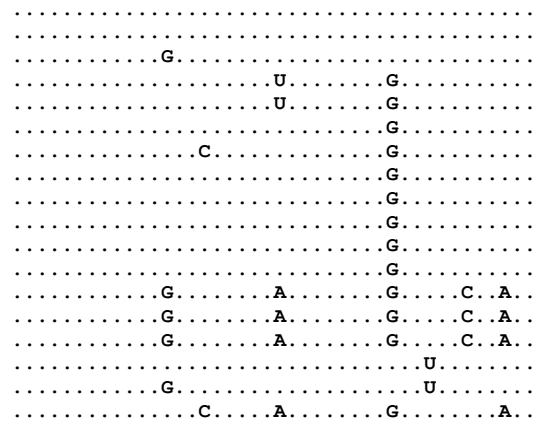

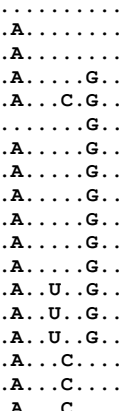

A.........

U.C..........

U..C....A.

(n)

U...C.

(u.

U.....

U.C.

u..c.

u. .c 

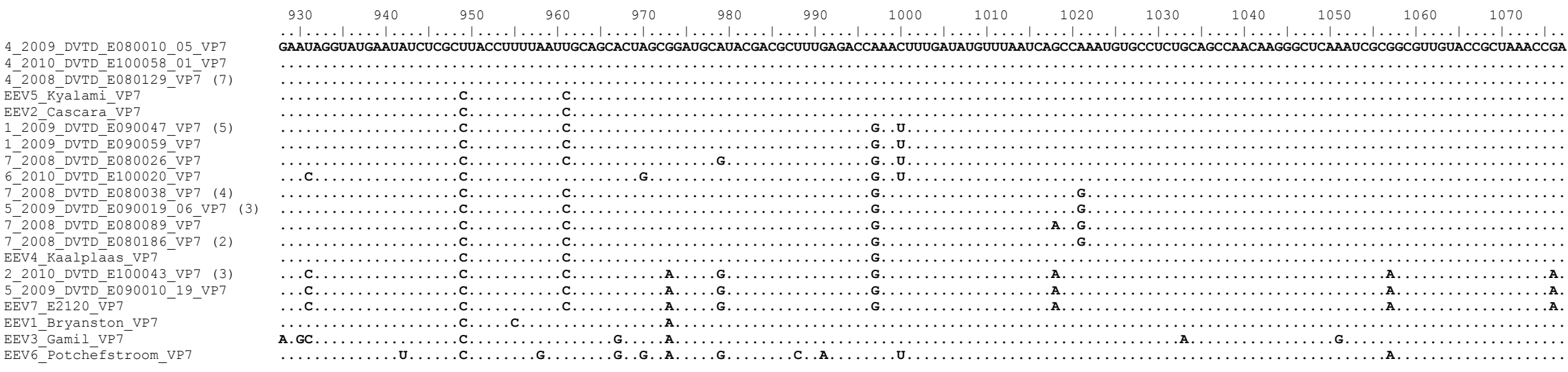

4_2009_DVTD E080010 05 VP7

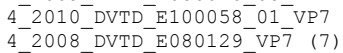
EEV5_KYalami_vP7

1.2009 DVTD Ē 090047 VP7 (5) 1.2009DVTDE 2090059 -VP7 6_2010_DVTD_E100020_VP7

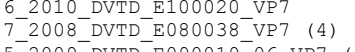
5-2009 DVTDEE090019-06 VP7 (3) 7 2008-DVTD E080186 VP7 (2) EĒEV4 Käalplàas VP7 5-2009_DVTDEE090010_19 VPP7

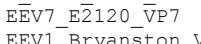

EEV1_Bryanston_VP7

EEV6-Potchefstroom_VP7

$\begin{array}{llll}1080 & 1090 & 1100 & 1110\end{array}$

112

113

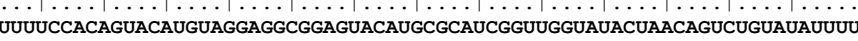

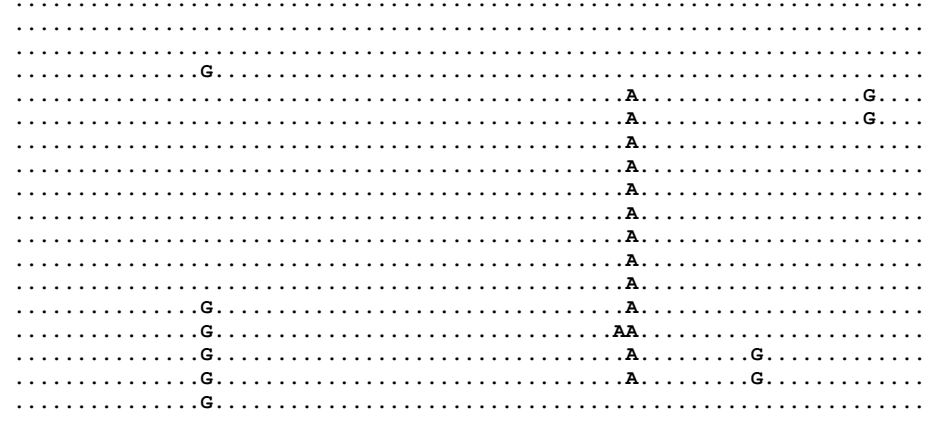

Figure S1. EEV S7 (VP7) gene sequences. Dots indicate identity and letters differences with the first sequence in the group. Identical sequences are represented only once in the figure and the number of identical sequences are indicated in brackets after the name of a random sequence in the group. The location of the real-time RT-PCR assay primers and probe are indicated by grey shaded boxes. 